\title{
COMPREENSIBILIDADE EM L2: UMA DISCUSSÃO SOBRE O EFEITO DA EXPERIÊNCIA DO OUVINTE E DO TIPO DE MEIO EM EXCERTOS DO PORTUGUÊS BRASILEIRO PRODUZIDOS POR UM FALANTE HAITIANO
}

\section{L2 Comprehensibility: A Discussion On The Role Of Listener Experience And Medium Type In Brazilian Portuguese Excerpts Produced By A Haitian Speaker}

\author{
Jeniffer Imaregna Alcantara de ALBUQUERQUE, UFRGS/UTFPR ${ }^{1}$ \\ Ubiratã Kickhofel ALVES, UFRGS ${ }^{2}$
}

\begin{abstract}
RESUMO: Este trabalho investiga o efeito da experiência (com fala não-nativa) de ouvintes brasileiros, bem como do tipo de meio (áudio ou áudio-vídeo) na compreensibilidade de excertos do Português Brasileiro produzidos por um aprendiz haitiano, do sexo masculino. O estudo foi conduzido com dois grupos de ouvintes brasileiros, com 20 participantes cada, sendo um composto por professores com experiência no ensino de português como língua adicional para haitianos (GP) e, o outro, por graduandos de um curso de Letras Português-Inglês, sem experiência com a fala de haitianos (GA). Entre os resultados estatísticos, testes Two-Way ANOVA intersujeitos demonstraram um efeito principal de experiência, i.e., o GP apresentou um maior índice de compreensibilidade quando comparado com o GA. No entanto, não foi encontrado um efeito principal de tipo de meio, e tampouco se verificou um efeito de interação entre as duas variáveis independentes (experiência e tipo de meio). A partir dos resultados, propõe-se uma reflexão teórico-metodológica sobre o conceito de 'compreensibilidade' de fala estrangeira que o entenda como propriedades compartilhadas entre falante e ouvinte, o que implica assumir que uma fala estrangeira passa por variáveis sociolinguísticas associadas a ambas as partes da interlocução.
\end{abstract}

PALAVRAS-CHAVE: Português como Língua Adicional; Aprendizes haitianos; Compreensibilidade; Experiência; Multimodalidade da fala.

ABSTRACT: This study investigates the effect of experience (with non-native spoken speech) of Brazilian listeners, as well as the type of medium (audio or audio-video) in the comprehensibility of Brazilian Portuguese excerpts produced by a male Haitian learner. The study was conducted with 2 groups, with 20 Brazilian listeners in each group, the first composed of experienced PAL (Portuguese as an Additional Language) teachers and the second formed by undergraduate students of both Portuguese-English (Literature and Linguistics) majors, with no experience with Haitians. Among the statistics results, the Two-Way ANOVA for independent samples revealed an effect of experience, i.e., the group of teachers presented higher comprehensibility rates when

\footnotetext{
${ }^{1}$ Doutoranda em Letras pela Universidade Federal do Rio Grande do Sul e professora de Inglês e Português para Falantes de Outras Línguas na UTFPR. jeniffer.albuquerque@ gmail.com

2 Professor Doutor na Universidade Federal do Rio Grande do Sul, pesquisador do CNPq. ukalves@gmail.com
} 
compared to the undergraduate students. However, it was neither found a type of medium effect, nor an interaction effect between the independent variables of experience and medium type. Taking the data into account, this study proposes a theoretical-methodological discussion upon the comprehensibility' concept of foreign spoken language, by seeing it as shared properties between speaker and listener. This implies that foreign speech is embedded in sociolinguistic variables, which are associated to both parts of the interlocution.

KEYWORDS: Portuguese as an Additional Language; Haitians; Comprehensibility; Experience; Speech Multimodality.

\section{INTRODUÇÃO}

Trabalhos relacionados a contextos de aprendizado de Segunda Língua ou Língua Estrangeira ${ }^{3}$, em especial os que se debruçam sobre a percepção de sons da fala, têm se voltado para o estudo de questões associadas aos conceitos de inteligibilidade e compreensibilidade (MUNRO; DERWING, 1995a, 1995b; DERWING; MUNRO, 1997, 2005, DERWING; MUNRO; WIEBE, 1998; DERWING; MUNRO; THOMSON, 2007; CRUZ, 2007, BECKER, 2013, O’BRIEN, 2014). Os resultados das investigações supracitadas são consonantes ao que autores como Abercrombie (1949, p.1204) já anunciavam em relação à necessidade/possibilidade de os aprendizes de línguas estrangeiras apresentarem uma "pronúncia confortavelmente inteligível", ou seja, para fins de comunicação não seria obrigatório o uso de construções sonoras, lexicais e sintáticas semelhantes ao falar nativo, desde que estas sejam inteligíveis e compreensíveis.

No entanto, apesar da gama de trabalhos que propõem investigar construtos como a inteligibilidade, nacional e internacionalmente (ALVES, 2015), parece haver uma divergência no que diz respeito tanto às definições teóricas, quanto às metodologias de testagem deste construto, como relata Cruz (2007), em seu

\footnotetext{
${ }^{3}$ É mister apontar que os termos 'língua adicional', 'língua estrangeira' e 'segunda língua (L2)' serão utilizados neste texto intercambiavelmente, uma vez que, embora a condição de aprendizagem da amostra da população aqui analisada (aprendizes haitianos) seja a de Português como Língua Adicional, tem-se como pano de fundo uma concepção de língua que abarca o entendimento dos termos acima mencionados.

${ }^{4}$ Trecho original: "[...] language learners need no more than a comfortably intelligible pronunciation", (ABERCOMBRIE, 1949, p.120)

5 Tradução dos autores.
} 
levantamento bibliográfico sobre pesquisas na área de inteligibilidade de fala conduzidas entre 1950-2003. Na esteira de levantamentos como os de Cruz (op cit) é possível acompanhar, também, o desenvolvimento da agenda de estudos sobre inteligibilidade e compreensibilidade, tanto na investigação de variáveis extralinguísticas ${ }^{6}$ que podem afetar os construtos mencionados (MUNRO; DERWING, 2015a) - como idade de aquisição, quantidade e qualidade da exposição linguística, feedback corretivo, proximidade entre as línguas materna e alvo -, quanto de variáveis linguísticas e das relacionadas ao delineamento experimental (FIELD, 2005; KOIZUMI; IN'NAMI，2012; TROFIMOVICH; ISAACS，2012; KAZUYA; TROFIMOVICH; ISAACS, 2015).

Após 60 anos de pesquisas na área, observa-se, também, um movimento de reflexão epistemológica em relação à acurácia dos resultados apresentados pelos experimentos que investigam construtos como inteligibilidade e compreensibilidade. Estudos como os de Lindemann; Subtirelu (2013), além de atribuírem contribuições referentes ao papel do ouvinte e não só do falante na atribuição do quão inteligível uma dada mensagem pode ser, sugerem que se leve em consideração a subjetividade empregada pelos ouvintes na aferição de sotaque estrangeiro, por exemplo. Além de apresentarem estudos que mostram que o ouvinte pode ser enviesado por características extra-linguísticas, como a nacionalidade do falante (RUBIN, 1992, apud LINDEMANN; SUBTIRELU, 2013), os autores chamam atenção para o fato de a inteligibilidade não estar alocada apenas no falante ou ouvinte, sendo algo compartilhado por ambos.

Diante deste cenário, delineamento experimental e construtos teóricos parecem caminhar para a incorporação de novos modos de testagem e por uma visão mais holística de construtos como inteligibilidade e compreensibilidade. Nesta direção, aspectos relacionados à multimodalidade da fala (FOWLER, 1996, 2010; FOWLER; HODGES, 2011) podem oferecer insumo teórico-metodológico para que se discuta

\footnotetext{
${ }^{6} \mathrm{Na}$ esteira de Kupske (2016), entende-se que dentro de uma perspectiva de língua como Sistema Adaptativo Complexo (SAC), visão que também é adotada por esse trabalho, não há uma divisão dicotômica entre variáveis linguísticas e extra-linguísticas, i.e., o conhecimento linguístico que um aprendiz tem/desenvolve sobre a língua compreende o que a literatura chama de variáveis extralinguísticas (e.g. as relacionadas a aspectos sociais e atitudinais). No entanto, como a adoção de língua como SAC é uma visão relativamente nova, serão utilizados, ao longo do trabalho, ambos os termos a fim de se discutir com trabalhos da área, mas não de modo a entendê-los como dissociáveis.
} 
como o indivíduo captura a informação que recebe do ambiente (entendendo-se 'ambiente' como tudo o que cerca o indivíduo, inclusive outros falantes, cf. FOWLER, 2010; FOWLER \& HODGES, 2011). Mais especificamente, Fowler (2010) discorre sobre a relevância e saliência perceptual das informações capturadas via diferentes meios, como áudio e/ou vídeo-áudio (compreendendo o aspecto visual como gestos orais, faciais e manuais).

Com base no que foi exposto, este artigo visa a trazer, para a discussão téoricometodológica de estudos sobre compreensibilidade de fala estrangeira, insumos sobre a natureza multimodal da fala, tendo como base dados de um aprendiz haitiano de português brasileiro (PB).

Para tanto, este artigo se encontra organizado de modo que a seção 2 traga uma breve resenha dos construtos 'inteligibilidade' e 'compreensibilidade', fazendo incursões teórico-metodológicas sobre questões relacionadas à natureza multimodal da fala. Após isso, a seção 3 contempla os achados de um experimento de compreensibilidade com um aprendiz haitiano, falante de português brasileiro como língua estrangeira, e abre para um possível diálogo com teorias da percepção da fala e para um entendimento mais amplo da relação entre falante e ouvinte. Por fim, a seção de discussão reúne as reflexões tecidas ao longo do estudo e aponta para trabalhos futuros.

\section{INTELIGIBILIDADE, COMPREENSIBILIDADE, GRAU DE ACENTO EM L2}

\section{Algumas visões sobre inteligibilidade e compreensibilidade}

De acordo com Cruz (2007b), Munro; Derwing (2015a), Gonçalves; Silveira (2015), Schwartzhaupt (2015) e Alves (2015), construtos como 'inteligibilidade' e 'compreensibilidade' vêm percorrendo uma longa caminhada, que trouxe não só diferentes entendimentos dos termos, bem como metodologias de testagem distintas. A partir disso, Schwartzhaupt (2015, p.31-34) menciona que a definição do construto de inteligibilidade é bastante volátil, uma vez que essa sofre modificações a partir de como tal construto é mensurado e verificado, i.e., o modo como cada autor se propõe a testar inteligibilidade, compreensibilidade e/ou outros termos acaba por definir o construto, e não o construto definindo o modo de testagem. A partir dessa premissa, ainda que não se espere esgotar todos os nuances conceituais dos construtos, é mister trazer algumas definições que aproximam e, ao mesmo tempo, contrapõem os construtos entre si. 
De acordo com Derwing; Munro (2015a), o conceito de inteligibilidade estaria associado ao entendimento do significado de um dado enunciado em sua extensão e é operacionalizado a partir de ditados, perguntas de compreensão, sentenças verdadeiras e falsas, etc. É importante apontar que Derwing; Munro (op cit), ao discutir o construto 'inteligibilidade', o fazem procurando associá-lo ao entendimento projetado pelo falante, pretendido por ele. A relação entre falante, mensagem e ouvinte parece se dar em uma linha tal qual uma ponte, posicionando falante e ouvinte nos extremos e, talvez, unidirecionalizando o entendimento da mensagem, ou seja, do que é proferido pelo falante e entendido pelo ouvinte. Se, por um lado, tem-se empregado o conceito de entendimento ao de inteligibilidade, por outro, autores como Smith; Nelson (1985) apontavam para algo que poderia ser alocado em dois "graus" de entendimento, sendo ‘inteligibilidade' associada às “formas linguísticas” e, 'compreensibilidade', num certo sentido, como um entendimento mais holístico do enunciado, uma vez que recuperaria "o significado maior do enunciado". Nesta obra, os autores fazem um levantamento sobre o uso do termo 'inteligibilidade' e definem tal construto como sendo o "reconhecimento da palavra ou enunciado" (SMITH;NELSON, op cit, p. 334), compreensibilidade como o "significado da palavra ou do enunciado (força locucionária)" e interpretabilidade, o "significado por trás da palavra ou do enunciado (força ilocucionária)". Além disso, os autores denotam como inteligibilidade o que não está relacionado ao falante ou ouvinte propriamente, mas sim como algo interacional entre falante e ouvinte. A inteligibilidade não é, portanto, constante, pois ela nem sempre tem como parâmetro de aferição/verificação o falante nativo; quanto maior o envolvimento (não só a exposição) um ouvinte tiver com um indivíduo ou com uma variedade, mais inteligível será a pessoa. Assim, as expectativas dos ouvintes são muito importantes, pois uma vez que o ouvinte tenha como expectativa inicial entender o falante em questão, ele terá mais chances de considerá-lo inteligível. Ainda, segundo os autores, inteligibilidade, compreensibilidade e interpretabilidade não possuem o mesmo peso e, portanto, não seriam intercambiáveis, uma vez que os erros/deslizes que podem causar mais problemas para a comunicação são os relacionados à 'compreensibilidade' e à 'interpretabilidade'.

Assim, outros autores além de Smith; Nelson (op cit) começaram a tecer considerações sobre diferenças entre inteligibilidade e compreensibilidade, uma vez que questões de entendimento ou compreensão em graus/níveis distintos parecem operar em diversos atos de comunicação entre falantes. A partir da distinção entre os construtos, 
segundo Derwing; Munro (2015a), a compreensibilidade estaria relacionada ao grau de esforço, com a facilidade ou dificuldade que um dado ouvinte tem para compreender um falante. Segundo os autores, o modo de testagem se resume ao julgamento em uma escala Likert de 1 a 9, por exemplo, sendo 1 'muito fácil' de compreender e, 9, 'muito difícil' de compreender.

Diante do exposto, percebe-se que, apesar de existirem algumas diferenças sobre o entendimento entre os construtos de 'inteligibilidade' e 'compreensibilidade', é possível observar, a partir da breve resenha de alguns teóricos, que a agenda de pesquisas na área tem trazido novas reflexões e distinções entre um entendimento mais local ou global do enunciado, por exemplo. Tais reflexões são importantes na medida em que há a promoção de uma investigação mais aprofundada sobre a concepção de desenvolvimento linguístico que subjaz os construtos supracitados. Nessa direção, este trabalho, para fins de encaminhamento teórico-metodológico, lança mão das definições tais quais estabelecidas por Derwing; Munro (2015a).

\section{Inteligibilidade e Compreensibilidade de fala estrangeira: reflexões teórico- metodológicas sobre multimodalidade da fala}

Como foi mencionado no início da seção anterior, o construto 'inteligibilidade' passou por reflexões teórico-metodológicas que trouxeram outros entendimentos do que viria a ser uma compreensão local ou global de um enunciado, culminando no surgimento de outro construto, a compreensibilidade. Apesar de trabalhos como os de Cruz (2007) mencionarem a necessidade de se investigar mais de um construto ao mesmo tempo, alguns trabalhos optam por investigar, por vezes, apenas alguns destes construtos, ou até eleger apenas um como foco de estudo. Há, segundo Derwing et al. (2014), uma não necessidade de interdependência entre os construtos de inteligibilidade e grau de acento ou compreensibilidade e grau de acento ou, até, entre os três. É interessante notar, por um lado, que apesar de inicialmente se investigar a inteligibilidade de fala estrangeira, alguns trabalhos têm optado por investigar a compreensibilidade ${ }^{7}$, aliada a testes de inteligibilidade, ou ainda, de maneira isolada.

\footnotetext{
${ }^{7}$ Para esta discussão, conforme mencionado na seção anterior, adota-se o conceito de 'compreensibilidade' tal como Derwing; Munro (2015a), i.e., o construto se define pelo grau de esforço feito pelo ouvinte para compreender os enunciados produzidos pelo falante.
} 
A decisão teórica e empírica para se realizar estudos em compreensibilidade de L2 parece estar pautada no entendimento da literatura da área de que o construto supracitado seria mais holístico, i.e., ao contemplar diversos níveis linguísticos (fonético, sintático, pragmático, lexical), o conceito de compreensibilidade seria capaz de abarcar a relação falante e ouvinte, além de abarcar fenômenos segmentais e suprassegmentais (DERWING; MUNRO, 1997; CASPERS, 2010). Apesar da existente crítica em relação aos testes de compreensibilidade, por esses lançarem mão da experiência subjetiva dos ouvintes para o julgamento de enunciados (o que pode ser um fator dificultador em relação à manipulação empírica), o processamento relacionado à fluência de um falante não-nativo, segundo Trofimovich; Isaacs (2012), passa por alguns aspectos de compreensibilidade, mas não necessariamente por questões de inteligibilidade. Ou seja, compreensibilidade seria, segundo os autores, um construto mais holístico, que abarcaria questões relacionadas ao significado dos enunciados produzidos em uma situação comunicativa e, assim, incluiria um processo de testagem distinto de construtos como inteligibilidade ${ }^{8}$. A partir de aspectos como esse, abre-se um espaço de reflexão sobre a escolha do quê, por quê e como testar.

Estudos nas áreas de psicolinguística e neuropsicologia relatam achados sobre a multimodalidade da fala em relação à inteligibilidade e à compreensibilidade ${ }^{9}$ de enunciados. O experimento de McGettigan et al. (2012) investiga as diferentes respostas neurais em relação à exposição de pistas, a saber auditivas, visuais e linguísticas, com o objetivo de verificar o efeito de cada uma destas informações, ou da interação entre elas, em construtos como a inteligibilidade. Apesar do estudo apresentar dados interessantes em relação à atividade cerebral, procurando contribuir com pesquisas que relacionam o funcionamento do córtex (parte responsável pelo pensamento e, mais especificamente, pela linguagem, julgamento e percepção) e outras áreas do cérebro na percepção da fala humana, procura-se focar, aqui, nos achados relacionados à inteligibilidade. Os autores apontam que, mais do que um efeito de cada tipo de informação, a interação entre as

\footnotetext{
${ }^{8}$ A discussão disposta nesse trecho se coaduna com a visão de inteligibilidade, interpretabilidade e compreensibilidade seguida por Smith;Nelson (1985), a qual prevê uma interação do nível de produção sonora com níveis semânticos e pragmáticos.

${ }^{9}$ É importante apontar que McGettigan et al. (2012) não deixam claro sua concepção do construto de 'inteligibilidade'. Assim, apesar de o estudo dos autores trazer pistas empíricas para a entendimento do construto, a concepção não é, necessariamente, a mesma que a de Derwing; Munro (2015a), a qual é seguida por este trabalho.
} 
pistas visuais, auditivas e linguísticas promoveu uma maior atividade cerebral na região do córtex frontal e lateral, possibilitado percentuais de inteligibilidade maiores. Apesar de os autores também terem encontrado um percentual de atividade lateral, que estaria relacionada com os canais auditivos, tal atividade não superou a atividade da região frontal, a qual promove o envolvimento de mais de um tipo de informação. Embora os resultados de McGettigan et al. (2012) tragam contribuições interessantes para os estudos em inteligibilidade e compreensibilidade, o entendimento do construto para a neuropsicologia pode ser distinto em relação ao que tem se utilizado na linguística e, mais especificamente, na linguística aplicada. Tal asserção se evidencia na preocupação que os autores possuem em inserir o construto de inteligibilidade talvez como algo próximo à percepção, procurando dar um tratamento mais holístico ao construto ao trazerem aspectos cognitivos para os testes. Apesar desta ressalva, aponta-se, por outro lado, que a contribuição de outras áreas do conhecimento pode trazer novos questionamentos para a discussão teórico-metodológica dos construtos 'inteligibilidade', 'compreensibilidade' e 'grau de acento', por esses serem afetados por questões objetivas e subjetivas, linguísticas e extra-linguísticas e, assim, se beneficiarem de um olhar multifacetado.

Lindemann; Subtirelu (2013), ao relatarem diversos estudos relacionados à influência de aspectos extra-linguísticos em experimentos de inteligibilidade e compreensibilidade, especificamente, trazem achados interessantes que apontam para a influência do dado visual na verificação de inteligibilidade ${ }^{10}$. Ao resenharem a série de estudos conduzidos por Rubin (1992, apud LINDEMANN; SUBTIRELU, op cit), os autores mencionam que alunos de graduação foram expostos a uma palestra de curta duração em inglês para verificarem a inteligibilidade de dois falantes (ambos nativos de inglês, mas com características físicas que denotavam que um deles poderia não ser nativo), sendo que em um dado momento, os alunos (também nativos de inglês), ao escutarem uma das palestras, visualizavam a imagem de uma mulher asiática e, em outro, a de uma mulher caucasiana. No entanto, ambos os áudios pertenciam à mesma falante. Entre os resultados dos estudos, se verificou que os estudantes conferiram um grau de inteligibilidade menor quando expostos à imagem da mulher asiática, levando

\footnotetext{
${ }^{10}$ Apesar de lidarem com o construto de inteligibilidade, é importante mencionar que, assim como no trabalho de McGettigan et al. (2012), o entendimento de Lindemann; Subitirelu (2013) difere do de Derwing; Munro (2015a).
} 
Lindemann; Subtirelu (op cit) a tecerem considerações sobre a influência da expectativa e de estereótipos no julgamento de informações linguísticas. Apesar de os próprios autores reconhecerem que a influência em questão possa afetar a análise dos resultados finais de um estudo de inteligibilidade, por exemplo, não se deve aferir que todo o experimento estaria enviesado, mas que é latente a possibilidade de os resultados serem explicados não só pelo julgamento linguístico dos ouvintes, mas também por variáveis extra-linguísticas.

Entre estudos alocados em áreas distintas, a saber, fonética-fonologia, psicolínguística, neuropsicologia, línguística aplicada, nota-se que, apesar de provindos de bases epistemológicas diferentes, todos parecem investigar a natureza multimodal da fala. O diálogo entre esses trabalhos, em princípio tão distintos, não está necessariamente posto, sendo importante considerar que se trata de um exercício teórico-metodológico de inteira responsabilidade das reflexões construídas neste artigo. No entanto, como pode ser visto, concebemos que o papel da visão, aliada a outros meios/tipos de informação, influencia no entendimento e compreensão de fala estrangeira. Assim, passa-se à discussão de um estudo com dados do PB como língua estrangeira (LE) que procurou oferecer insumos teórico-metodológicos para a reflexão sobre a natureza multimodal da comunicação em relação à compreensibilidade.

\section{O EXPERIMENTO: OBJETIVOS, HIPÓTESES E PARTICIPANTES}

O estudo teve como objetivo verificar o efeito da experiência (com dois grupos de ouvintes, a saber: professores de português para estrangeiros, grupo GP, e alunos do curso de Letras Português-Inglês, grupo GA) e do tipo de meio (áudio ou áudio-vídeo) na compreensibilidade de excertos do Português Brasileiro (PB) produzidos por um aprendiz haitiano. Esperava-se encontrar efeitos das variáveis 'experiência' e 'tipo de meio', em relação à compreensibilidade do Português Brasileiro, conforme se encontra na descrição das 3 hipóteses deste estudo:

Hipótese 1: GP e GA atribuirão diferentes índices de compreensibilidade em relação aos estímulos do falante haitiano.

Motivação: Evidências da influência de fatores como experiência (contato com fala estrangeira): Flege (1995), Fowler; Hodges (2011). 
Hipótese 2: GP e GA atribuirão índices diferentes de compreensibilidade em relação ao tipo de meio (estímulos de ‘áudio-vídeo' e ‘áudio').

Motivação: Evidência de tipos de meios perceptuais na percepção da fala via construto de multimodalidade: Fowler (1986); Fowler; Hodges (2011).

Hipótese 3: Haverá um efeito de interação entre as variáveis 'tipo de meio' e 'experiência', de modo que GP atribuirá maiores índices de compreensibilidade por ser exposto ao 'tipo de meio' áudio-vídeo e por ter mais 'experiência' com os alunos haitianos do que GA.

Motivação: Evidências da influência de outros meios, como a imagem em julgamento de inteligibilidade e compreensibilidade com grupos com diferentes tipos de experiência com estrangeiros: Lindemann (2010), Lindemann; Subtirelu (2013).

O delineamento experimental do estudo adota um delineamento experimental 2X2, sendo uma das variáveis independentes a experiência com o português falado por haitianos (GP, grupo com experiência; GA, grupo sem experiência), e a outra a modalidade de apresentação dos dados de fala (áudio e áudio-vídeo). A variável dependente foi a compreensibilidade, medida a partir da compreensão de trechos de 3 narrativas orais, semi-estruturadas, em uma escala de 9 pontos, sendo 1 'muito fácil' de compreender e, 9, 'muito difícil' de compreender.

Em relação ao design do estudo, é importante mencionar que este foi fatorial, uma vez que possuía duas variáveis independentes, as quais foram estudadas para verificar, por um lado, o efeito que cada uma tinha sobre a variável dependente (efeito principal) e, por outro, como elas interagiram entre si (efeito de interação).

Ao total, o estudo contou com uma amostra de 40 sujeitos. Conforme mencionado anteriormente, foi realizado um agrupamento destes sujeitos em relação à variável 'experiência' com o português como L2 produzido por falantes haitianos. Assim, foram selecionados 20 para o GA, 11 mulheres e 9 homens, sendo todos alunos do curso de Letras Português-Inglês da Universidade Tecnológica Federal do Paraná (UTFPR) e 20 para o GP, 14 mulheres e 6 homens, sendo todos professores de Português como Língua Adicional no projeto Português para Migração Humanitária da UFPR (PBMIH). As idades variaram entre 18 e 35 anos (média=22.6; desvio padrão = 4.8) para o GA, e entre 21 e 60 anos (média $=26.5$; desvio padrão $=8.4$ ) para o GP. Todos os participantes estavam realizando a formação em Letras no GA, ou já possuíam 
formação em Letras, no caso do GP. Além disso, todos os participantes residiam em Curitiba no momento da coleta de dados.

Todos os participantes do GA possuíam inglês como L2 e, entre os do GP, 12 possuíam inglês, 6 espanhol e 2 alemão. Assim, pode-se notar que nenhum deles tinha um conhecimento declarado de Francês, o que para o presente estudo foi importante, uma vez que o crioulo haitiano, L1 dos haitianos, é de base francesa, e tal aspecto poderia atuar como uma variável externa. Outro dado importante a ser mencionado é o contato com estrangeiros, sendo que do GA, 14 nunca haviam tido contato com estrangeiros e 6 haviam, mas nenhum com falantes haitianos, e, no GP, todos os participantes haviam tido contato com estrangeiros e ministravam aulas a haitianos há cerca de 2 anos. É importante mencionar que os participantes foram divididos, incialmente, em 2 grupos: GA e GP. Em relação à exposição aos dados, é mister dizer que dentro do GA e GP, metade dos participantes foram expostos apenas aos estímulos no tipo de meio áudio, e a outra metade foi exposta somente ao áudio-vídeo.

Em relação ao falante haitiano, utilizou-se um locutor haitiano, de 25 anos, que estava há 1 ano e meio no Brasil, na cidade de Curitiba, no momento de coleta dos dados. O locutor falava crioulo-haitiano, francês, e estava adquirindo o português em aulas regulares na UTFPR (que compreendiam um montante de 4 horas semanais) no momento de coleta dos dados.

\section{Materiais e Instrumentos}

O estudo contou com termos de consentimento e de autorização de cessão de direitos de imagem e áudio, os quais foram assinados por ambos os grupos GA e GP e pelo locutor haitiano. Ambos os grupos de ouvintes preencheram um Questionário de Histórico da Linguagem (adaptado de SCHOLL; FINGER 2013), que reúne informações acerca do perfil pessoal dos participantes, bem como de sua experiência com ensino de português para estrangeiros, e do contato com estrangeiros.

Sobre os excertos aos quais GA e GP foram expostos, esses provinham de 3 histórias em quadrinhos (a Suitcase Story, retirada de DERWING et al., 2009, e as outras duas de um compêndio de histórias do Snoopy - The Complete Peanuts, 2006). Assim como em outros estudos da área (DERWING et al., 2007; DERWING et al., 2009; TROFIMOVICH; ISAACS, 2012, entre outros), as histórias foram utilizadas como elementos orais de narração de eventos, uma vez que são estímulos 
contextualizados e possuem um encadeamento sintático-pragmático passível de ser gravado sem que seja extremamente controlado, i.e., o participante conta a história lançando mão de recursos linguísticos (lexicais, fonéticos, prosódicos, sintáticos, pragmáticos, gestuais) aos quais tem acesso. Todas as histórias continham mais ou menos o mesmo número de quadrinhos e personagens. É importante mencionar que todas as histórias eram do mesmo gênero e tipo textual, com vocabulário que compreendia elementos lexicais conhecidos pelo falante haitiano. $\mathrm{O}$ aluno haitiano apresentou uma dificuldade inicial com a tarefa, não necessariamente com o vocabulário e interpretação das imagens, i.e., o processo de entender que a narração dele seria gravada e que não havia um jeito "certo" de narrar, mas que ele poderia narrar do modo como achasse melhor desde que fiel à história disposta dos quadrinhos. Após este primeiro momento, o aprendiz não demonstrou dificuldades no cumprimento da tarefa.

A tarefa de compreensibilidade, confeccionada e aplicada no software $\mathrm{TP}^{11}$, versão 3.1 (RAUBER et al., 2012), consistiu na apresentação de estímulos auditivos e visuais-auditivos, com uma opção de 'ok' para quando a gravação terminasse e com uma escala de 9 pontos, utilizada pelos participantes como julgamento do grau de dificuldade com os excertos (sendo que 1 designava que o áudio era 'muito fácil' de se compreender e 9, 'muito difícil' de se compreender). Cada ouvinte avaliou um montante de 60 excertos, sendo 30 áudio-vídeo e 30 apenas na mídia áudio, todos retirados das narrativas já apresentadas previamente neste trabalho. Além disso, de maneira a se familiarizarem com a dinâmica do teste, foi aplicado um teste de familiarização, que contava com 10 excertos, sendo 5 em áudio-vídeo e 5 apenas em áudio.

\section{Gravação e edição de estímulos}

Seguiram-se os parâmetros de edição de estímulos propostos por O’Brien (2014), a saber: fonológicos (inadequações segmentais, suprassegmentais, pitch), fluência (presença e duração de pausas sem preenchimento, presença e duração de pausas com preenchimento, repetições e autocorreção, taxa de elocução, taxa

${ }^{11}$ O TP é um software livre, no qual é possível que sejam feitos diversos testes de percepção, inteligibilidade e compreensibilidade de fala. Ele pode ser baixado no endereço: <http://www.worken.com.br/tp_regfree.php/>. 
articulatória, sendo esta última referente ao número de sílabas no momento de fonação) e recursos linguísticos (inadequações sintáticas, morfológicas e lexicais). De modo a exemplificar a edição feita, pode-se tomar o exemplo do excerto "Eu passar na grande rua" produzido pelo locutor a respeito da história-mote Suitcase Story. A seleção supracitada apresenta a sequência sonora sem pausas longas (causadas pela hesitação natural do falante ao narrar a história) e uma construção sintática que segue um padrão do PB de SVO (sujeito, verbo e objeto). As inadequações morfológicas (e relação ao uso do verbo no infinitivo) e sintáticas (inversão entre o vocábulo 'grande' e 'rua') forma mantidas e controladas, ou seja, o objetivo do experimento não consistia na retirada de tais inadequações, mas sim no controle das mesmas para que pudessem ser utilizadas na discussão posterior dos dados, caso os ouvintes avaliassem tais excertos como consistentemente menos compreensível.

Em relação à gravação, o áudio foi capturado com o auxílio de um gravador Tascam Dr-05, 24-bit/96kHz e do vídeo, com uma câmera NIKKON D5200 1,280 x 720 (720p) em 60p (59.94 fps). Os textos orais no formato de vídeo foram editados e balanceados com auxílio do software Audacity, versão $1.3 .5^{12}$, gravados e normalizados (-5dB de intensidade), e o áudio foi segmentado no software Praat version $5.374^{13}$ (BOERSMA;WEENINK, 2014). Todos os áudios e vídeos tinham uma duração média de 2 segundos. A gravação foi feita em uma sala sem tratamento acústico (na Universidade Tecnológica Federal do Paraná), que possuía pouca taxa de reverberação. Apesar de a gravação não ter sido realizada em um estúdio com tratamento acústico, um ambiente que não tenha tal tratamento não se apresenta como uma variável externa para este estudo, uma vez que se parte do entendimento de que, em uma situação comunicativa real, o informante experiencia todo o seu ambiente, seu entorno, inclusive o ruído externo (FOWLER, 1986; MACHRY DA SILVA, 2014).

\footnotetext{
${ }^{12} \mathrm{O}$ Audicity é um software livre utilizado para a gravação de dados. Pode ser encontrado para download no endereço: <http://www.audacityteam.org/>.

13 O Praat é um software livre cuja utilização se estende da gravação e análise acústica de dados à elaboração de testes perceptuais. O Praat pode ser encontrado no endereço: 〈wwww.praat.org〉.
} 


\section{Coleta dos dados}

O estudo foi conduzido de forma que todos os participantes realizaram todas as etapas na mesma sequência, individualmente. Primeiramente, assinaram o termo de consentimento, que continha informações sobre a tarefa que iriam realizar e, após isso, preencheram a ficha de identificação. A seguir, foram informados de que realizariam uma tarefa de familiarização, para que o teste no TP não fosse uma variável externa ao estudo. Após o teste de familiarização, os participantes poderiam fazer perguntas sobre a realização do teste, em especial em relação à escala de 9 pontos, pois muitas vezes a noção gradual de 1 , sendo fácil e 9, 'muito difícil' ${ }^{14}$, não era assimilada, de início, pelos participantes.

$\mathrm{Na}$ sequência, os participantes realizaram o teste de compreensibilidade. A ordem dos áudios e vídeos foi aleatorizada para cada participante, uma vez que efeitos de cansaço ou de lista poderiam ocorrer. O teste no software TP foi aleatorizado manualmente pela pesquisadora encarregada de preparar os testes, uma vez que o TP não aleatoriza arquivos separados. É importante mencionar que os membros de cada grupo, a saber GA e GP, não foram expostos a todos os estímulos. Após o controle do perfil dos ouvintes, a partir do Questionário de Histórico da Linguagem, delineou-se que 10 ouvintes do GA seriam expostos aos estímulos em áudio e 10 aos em áudio-vídeo e, da mesma forma, procedeu-se com os ouvintes do GP. Além disso, observa-se que não houve repetição dos estímulos ao longo do teste e que os ouvintes realizaram a tarefa em uma única sessão.

Em relação ao teste em si, os participantes foram convidados a se sentarem em uma cadeira, de frente para a tela do computador e a colocarem fones de ouvidos, para que os estímulos auditivos fossem otimizados. Todos os participantes realizaram o teste de compreensibilidade, individualmente, na mesma sala em que os estímulos foram gravados, para que se evitasse um efeito de ambiente. A rotina do teste se deu da seguinte maneira: o participante ouvia ou via o primeiro estímulo e, após o término deste, clicava no botão "ok", o qual aparecia no canto esquerdo da tela. Após apertar no botão "ok", a escala de 9 pontos aparecia e o participante clicava na opção que lhe

${ }^{14}$ É importante salientar que apesar de se estar ciente de que apresentar uma escala de 1 a 9, sendo 1 o "mais fácil" e 9 "o mais difícil", pode ser pouco intuitivo aos ouvintes, procurou-se manter o mesmo padrão de trabalhos como os de Derwing; Munro (2015), entre outros da área. 
parecesse mais adequada. Não foi permitido que os participantes ouvissem ou vissem os excertos mais de uma vez. A seguir, um segundo estímulo era apresentado, de forma sucessiva até o final da tarefa.

\section{RESULTADOS}

Os resultados apresentados nesta seção dizem respeito à média, por participante, de cada um dos excertos obtidos a partir da escala de 1 a 9. Em relação aos testes estatísticos, todos foram rodados no software SPSS versão 18. Após o teste de normalidade ter apontado que os dados estavam distribuídos normalmente, foi rodado o teste Two-Way ANOVA inter-sujeitos.

No Quadro 1 é possível visualizar as médias de compreensibilidade, correspondentes à escala de 1 a 9 pontos, para os grupos GA e GP, separados de acordo com o grau de 'experiência'. Como foi mencionado previamente, a previsão era de que a aferição de índices de compreensibilidade para o grupo GP seria maior do que para GA. A partir das médias dispostas no Quadro 1, observa-se que há uma diferença entre GA e GP, de modo que GP apresenta uma média mais alta do que GA.

\begin{tabular}{|l|c|c|c|}
\hline Grupo & Amostra (N) & Média & Desvio Padrão \\
\hline GP & 20 & 4,0350 & 1,74997 \\
\hline GA & 20 & 5,3800 & 1,71022 \\
\hline
\end{tabular}

Quadro 1: Resultados para o efeito da experiência nos grupos GA e GP.

Com relação aos resultados estatísticos, esses apontaram para a existência de um efeito principal de experiência no valor da escala de compreensibilidade, apresentando um valor de teste $\mathrm{F}(1,36)=6.135, \mathrm{p}=.018$. Este resultado indica que existe uma diferença significativa nos resultados dos grupos GA e GP, i.e., o GA, cujos participantes são graduandos de Letras Português-Inglês e não têm experiência com aprendizes de português como língua adicional, consideraram mais difícil compreender a fala do locutor haitiano do que os participantes do GP - professores que ministram aulas para alunos haitianos. Este resultado é respaldado por estudos que se debruçaram sobre percepção da fala (FLEGE, 1995) e, também, pelos relacionados à compreensibilidade de fala estrangeira (DERWING et al.,2007; DERWING; MUNRO,2009, TROFIMOVICH; ISAACS, 2012; O'BRIEN,2014, dentre outros). 
Com relação à variável 'tipo de meio', é possível notar que o Quadro 2 aponta para a proximidade das médias de compreensibilidade entre A (áudio) e AV (áudiovídeo) entre os grupos GA e GP.

\begin{tabular}{|c|c|c|c|}
\hline Grupo & Amostra (N) & Média & Desvio Padrão \\
\hline A (áudio) & 20 & 4,4650 & 1,80999 \\
\hline AV (áudio-vídeo) & 20 & 4,9500 & 1,88135 \\
\hline
\end{tabular}

Quadro 2: Resultados para o efeito de tipo de meio para os excertos em áudio e áudiovídeo.

Tais dados se refletem nos resultados estatísticos, uma vez que não foi encontrado um efeito principal para a variável 'tipo de meio', sendo que o resultado obtido no teste Two-Way ANOVA foi $\mathrm{F}(1,36)=.798 \mathrm{p}=.378$. Este resultado está atrelado ao fato de que a diferença entre os dados para o tipo de meio 'áudio' e 'áudiovídeo' não foi significativa, i.e., nenhum dos tipos de meio parece ter auxiliado mais na compreensão dos excertos para nenhum dos grupos. Ainda que não se tenha registro, até onde foi possível checar no referencial teórico da área, sobre estudos em compreensibilidade de L2 que verificassem os efeitos dos tipos de meio, uma vez que o presente trabalho tem por base a noção de multimodalidade (FOWLER, 1996, 2010; FOWLER; HODGES, 2011), seria esperado um efeito referente a essa variável. Tais resultados são, portanto, surpreendentes ${ }^{15}$.

Por fim, tampouco foi verificada uma interação entre as variáveis 'experiência' e 'tipo de meio', sendo que o resultado de interação do teste Two-Way ANOVA foi $\mathrm{F}(1,36)=1.783 \mathrm{p}=.190$. Em relação ao estudo, tal resultado revela que uma variável não afeta os resultados da outra, i.e., não há um efeito entre ter mais experiência com a compreensão de fala estrangeira e a dificuldade ou facilidade de recuperar informações a partir de meios distintos, a saber, áudio ou áudio-vídeo. Pensando do ponto de vista comunicacional, em que o ouvinte recebe informações via diferentes tipos de meio e de falantes distintos, seria possível esperar que houvesse uma relação entre tais variáveis. No entanto, para este estudo, tal hipótese não foi verificada.

\footnotetext{
${ }^{15}$ Uma maior discussão acerca de tais resultados será possibilitada quando discutirmos as limitações do presente trabalho, na conclusão do presente artigo.
} 


\section{DISCUSSÃO E CONSIDERAÇÕES FINAIS}

A partir do final da década de 80 e início da década de 90, estudos relacionados à percepção de níveis distintos da linguagem começaram a surgir e a investigar dificuldades relacionadas à compreensão da fala estrangeira. Tais investigações se debruçaram, por um lado, no entendimento de conceitos como inteligibilidade, acento, compreensibilidade, como os trabalhos de Derwing et al. (2007), Derwing; Munro (2009), Trofimovich e Isaacs (2012), O’Brien (2014), dentre outros e, por outro lado, ao se considerarem aspectos (como idade de aquisição, tempo de exposição à língua estrangeira, por exemplo) que podem influenciar na compreensão de um aprendiz, conforme nos estudos de Flege (1995), Derwing; Munro (2015a), entre outros.

Em relação ao estudo desenvolvido neste artigo, os resultados corroboraram a Hipótese 1, em geral, que previa um efeito principal de experiência. A literatura discute o efeito de experiência (FLEGE, 1995) como sendo o contato com a fala estrangeira; assim, quanto maior o contato com a fala de estrangeiros, por exemplo, mais fácil é a recuperação de informações gerais e específicas, uma vez que a atenção do indivíduo se desenvolve, continuamente, para não relacionar os sons providos de um falante estrangeiro como "estranhos" ou discrepantes, quando comparados com os que são produzidos por falantes nativos.

No entanto, não foi possível corroborar as Hipóteses 2 e 3, i.e., não se verificou nem uma diferença entre a compreensão de tipo de meio ou a interação entre as variáveis 'experiência' e 'tipo de meio'. Em relação a isso, algumas questões metodológicas podem ter influenciado e, portanto, conduzido a esse resultado. Primeiramente, o número de informantes da amostra, apesar de idêntico para os grupos GA e GP, foi pequeno em relação ao tamanho do efeito que se esperava. Assim, novos estudos com uma amostra maior precisam ser conduzidos. Além do tamanho da amostra, por mais que algumas variáveis em relação à gravação das narrativas tenham sido controladas, o fato de os participantes terem sido expostos a apenas um locutor pode ter gerado um viés idiossincrático, i.e., todas as inferências feitas pelos participantes em relação à fala estrangeira a que foram expostos foram realizadas a partir dos dados de um único falante, o que não provê exemplares suficientes para que os participantes realizassem generalizações mais amplas. No entanto, a escolha de ter apenas um locutor se deu pela disponibilidade do material humano, uma vez que, apesar de termos acesso a outros aprendizes haitianos, a maioria era conhecida do grupo GP, 
uma vez que os participantes deste grupo haviam ou estavam ministrando aulas para esses alunos no momento da coleta de dados. A escolha de outros aprendizes-possíveis locutores foi, portanto, inviabilizada, pois poderia acontecer um efeito de familiaridade com a voz e imagem do aprendiz e isso poderia afetar os dados. Nessa esteira, seria importante sugerir que fossem gravados estímulos com locutoras femininas, uma vez que pode ter havido um viés relacionado ao gênero. Além disso, outro aspecto a ser considerado diz respeito ao fato de que os participantes, dos grupos GA e GP tiveram acesso a apenas um tipo de meio, o que pode ter ocasionado dois problemas, a saber: a) é possível que alguns participantes sejam mais inclinados a recuperarem, com mais facilidade, informações via áudio e, se estes foram expostos ao tipo de meio áudiovídeo, sua compreensão pode ter sido prejudicada; b) o delineamento experimental em relação à quantidade de grupos de teste acaba sendo 4 e não 2 , como havia se previsto inicialmente (na etapa de projeto desta investigação), porém a comparação entre 4 grupos distintos pode não ser a melhor decisão metodológica, uma vez que demandaria um número ainda maior de participantes.

Para além dos aspectos apontados acima, questões metodológicas específicas relacionadas à maneira de testar o construto da compreensibilidade precisam passar por um refinamento, de modo a levar em conta os achados aqui encontrados.

Apesar das limitações supracitadas, acreditamos que os resultados prestam contribuições, tanto no plano empírico quanto no plano teórico, para as discussões sobre os construtos de 'inteligibilidade' e 'compreensibilidade' em L2. No que diz respeito ao plano empírico, chama-se atenção para o fato de que a maioria das pesquisas sobre os construtos supracitados apresentam dados da língua inglesa enquanto LE/L2. Assim, ao contemplar dados de Português como Língua Adicional sendo adquirido por um aprendiz haitiano, a discussão empírica se insere dentro do âmbito de uma reflexão sociolinguística a respeito das relações identitárias entre ouvintes brasileiros e falantes haitianos. Além disso, ao assumir que as relações comunicativas se dão sempre em um determinado contexto, entre grupos específicos de falantes e ouvintes, parece ser pertinente olhar para os dados de fala por mais de uma via, e. g., áudio e áudio-vídeo. No que diz respeito ao plano teórico, o trabalho acaba por fornecer insumos empíricos a 
concepção de compreensibilidade ${ }^{16}$, de modo geral, como um construto compartilhado entre falante e ouvinte. Além disso, embora se tratem de considerações iniciais, os resultados apontam para a necessidade de uma concepção mais clara de desenvolvimento linguístico dentro dos estudos de inteligibilidade e compreensibilidade.

Espera-se, com o presente trabalho, que os dados do Português como Língua Adicional possam alimentar a discussão teórico-empírica dos construtos de inteligibilidade e compreensibilidade. Além disso, aventa-se a necessidade de refletir sobre a concepção de desenvolvimento linguístico adotada por diferentes paradigmas teóricos/modelos que se debruçam sobre os construtos supracitados. Por fim, mas não menos importante, este trabalho procura promover a existência de um maior número de investigações, afim de verificar se os resultados aqui encontrados se aplicam a comunidades com diferentes tipos de contato com os aprendizes haitianos, tendo a possibilidade de, no futuro, contribuir com a elaboração de materiais didáticos e planos de ação em sala de aula para o processo de ensino-aprendizagem de novos contingentes populacionais.

\section{REFERÊNCIAS}

ABERCROMBIE, D. Teaching pronunciation. English Language Teaching, 3, p. 113$122,1949$.

ALVES, U. K. Ensino de pronúncia na sala de aula de língua estrangeira: questões de discussão a partir de uma concepção de língua como sistema adaptativo e complexo. Versalete, v. 3, pp. 392-413, 2015.

AUDACITY. Software disponível em: <http://www.audacityteam.org/>, versão 2.1.2, 2015.

BECKER, M. R. Inteligibilidade da língua inglesa sob o paradigma de Língua Franca: percepção de discursos de diferentes L1s por brasileiros. Tese (Doutorado). Universidade Federal do Paraná, 2013.

BOERSMA, P.; WEENINK, D. Praat: Doing Phonetics by Computer. Version 5.374. 2014. Disponível em: <www.praat.org>.Acesso em: 06 Dez. 2015.

${ }^{16}$ É importante mencionar que, apesar do trabalho ter como foco a 'compreensibilidade', os resultados podem lançar reflexões interessantes, também, para o construto de 'inteligibilidade', uma vez que, embora sejam distintos, possuem uma relação bastante próxima. 
CASPERS, J. The influence of erroneous stress position and segmental errors on intelligibility, comprehensibility and foreign accent in Dutch as a second language. Linguistics in the Netherlands, v.27, pp. 17-29, 2010.

CRUZ, N. C. Terminologies and definitions in the use of intelligibility: state-of-the-art. In Revista Brasileira de Linguística Aplicada, v. 7, n. 1, pp. 149-159, 2007.

DERWING, T. M.; MUNRO, M. J. ACCENT, INTELLIGIBILITY, AND COMPREHENSIBILITY. Studies in Second Language Acquisition, pp 1-16, 1997.

Second language accent and pronunciation teaching: a research-based approach., TESOL Quarterly, v. 39, n. 3, pp. 379-397, 2005.

The interface of teaching and research: what type of pronunciation instruction should L2 learners expect? In: LUCHINI, P. L; GARCÍA JURADO, M.A; ALVES, U. K. Fonética y Fonología: articulación entre enseñanza e investigación. Mar del Plata: Universidad Nacional de Mar del Plata, 2015a.

DERWING, T. M.; MUNRO, M.J.;FOOTE, J. A.; WAUGH, E.; FLEMING, J. Opening the window on comprehensible pronunciation after 19 years: a workplace training study. Language Learning, v. 64, n. 3, pp. 526- 548, 2014.

DERWING, T. M.; MUNRO. M.J.WIEBE, G. Evidence in favor of a broad framework for pronunciation instruction. Language Learning, v. 48, n. 3, pp. 393-410, 1998.

DERWING, T. M.; MUNRO, M.J.; THOMSON, R. A longitudinal study of learners' fluency and comprehensibility development. Applied Linguistics, v. 29, n. 3, pp. 359380, 2007.

DERWING, T. M.; MUNRO; ROSSITER, M. J. The relationship between L1 fluency and L2 fluency development. Studies in Second Language Acquisition, 31(4), 533-557, 2009.

FLEGE, J. E. Second-language speech learning: Theory, findings, and problems. In: STRANGE W. (Ed.), Speech perception and linguistic experience: Theoretical and methodological issues .Timonium, MD: York Press, 1995. pp. 229-273

FOWLER, C. A. Listeners do hear sounds, not tongues. The Journal of the Acoustical Society of America, v. 99, n. 3, pp. 1730-1741, 1996. 2010 .

Embodied, Embedded Language Use. Ecological Psychology, vol. 22, n. 4,

FOWLER, C.A. HODGES, B. Dynamics and languaging: toward an ecology of language. Ecological Psychology, v. 23,p p. 147-156, 2011.

FIELD, J. Intelligibility and the listener: the role of lexical stress. TESOL quarterly, v.39, n.3, pp.399-423, 2005.

GONÇALVES, A.; SILVEIRA, R. Intelligibility research in Brazil: empirical findings 
and methodological issues. Revista Horizontes de Linguística Aplicada, v. 14, n.1,pp. 51-81, 2015.

KAZUYA, S. TROFIMOVICH, P., ISAACS, T. "Second language speech production: Investigating linguistic correlates of comprehensibility and accentedness for learners at different ability levels." Applied Psycholinguistics 35, 2015.

KLUGE, D. C.; REIS, M. S.; NOBRE-OLIVEIRA, D.; BETTONI-TECHIO, M. The use of visual cues in the perception of English syllable-final nasals by Brazilian EFL learners. In: Watkins, M. A.; Rauber, A. S. \& Baptista, B. O. (Eds.). Recent Research in Second Language Phonetics/Phonology: Perception and Production. Cambridge Scholars Publishing, pp. 141-153, 2009.

Brazilian EFL learners'identification of word-final $/ \mathrm{m}-\mathrm{n} /$ : native/nonnative realizations and effect of visual cues. Tese (Doutorado). Universidade Federal de Santa Catarina,2009.

The effect of visual cues in the perception of nonnative contrast. Signotica (UFG), v. 22, n.2, p. 257-276, 2010.

KOIZUMI, R.,IN'NAMI, Y. Effects of text length on lexical diversity measures: using short texts with less than 200 tokens. System , v.40, n.4, pp. 554-564, 2012.

KUPSKE, F. Imigração, atrito e complexidade: a produção das oclusivas iniciais surdas do inglês e do português por sul-brasileiros residentes em Londres. Tese (Doutorado), Universidade Federal do Rio Grande do Sul, 2016.

LINDEMANN, S.; SUBTIRELU, N. Reliably biased: the role of listener expectation in the perception of Second Language Speech. Language Learning, v. 63, n. 3, pp. 567$594,2013$.

MACHRY DA SILVA, S. Aprendizagem fonológica e alofônica em L2: Percepção e produção das vogais médias do português por falantes nativos do espanhol. Tese (Doutorado ). Pontifícia Universidade Católica do Rio Grande do Sul, 2014.

MCGETTIGAN, C. FAULKNER; ALTARELLI; OBLESER; BAVERSTOCK; SCOTT. "Speech comprehension aided by multiple modalities: Behavioural and neural interactions." Neuropsychologia 50.5, pp.762-776, 2012.

MUNRO, M.; DERWING, T. J. Foreign accent, comprehensibility and intelligibility in the speech of second language learners. Language Learning, v. 45, n.1, pp. 73-97, 1995a.

Processing time, accent and comprehensibility in the perception of native and foreign accented speech. Language \& Speech, v. 38, n.3, pp. 289-306, Jul-Set1995b.

O'BRIEN, M. G. L2 learners' assessments of accentedness, fluency and comprehensibility of native and nonnative German speech. Language Learning, v.64, n.4, pp.715-748, 2014. 
RAUBER, A., RATO, A., KLUGE, D., SANTOS, G. TP, v. 3.1 [Application software]. Disponível em: http://www.worken.com.br/tp_regfree.php/, 2012.

SCHOLL, A. P. ; FINGER, I. Elaboração de um questionário de histórico da linguagem para pesquisas com bilíngues. Nonada: Letras em revista, v. 2, n.21, pp. 1-17, 2013.

SCHWARTZHAUPT, B. M. Testing intelligibility in English: the effects of Positive VOT and contextual information in a sentence-transcription task. Dissertação (Mestrado). Universidade Federal do Rio Grande do Sul, 2015.

SMITH, L. E.;NELSON, C. International intelligibility of English: directions and resources. World Englishes, v. 4, n. 3, pp. 333-342, 1985.

TROFIMOVICH, P. \& ISAACS, T. Disentangling accent from comprehensibility. Bilingualism: Language and Cognition,v, 15, n.4, pp.905-916, 2012. 